\title{
A Critical Role for the Potassium-Dependent Sodium-Calcium Exchanger NCKX2 in Protection against Focal Ischemic Brain Damage
}

\author{
Ornella Cuomo, ${ }^{1}$ Rosaria Gala, ${ }^{1}$ Giuseppe Pignataro, ${ }^{1}$ Francesca Boscia, ${ }^{1}$ Agnese Secondo, ${ }^{1}$ Antonella Scorziello, ${ }^{1}$ \\ Anna Pannaccione, ${ }^{1}$ Davide Viggiano, ${ }^{1}$ Annagrazia Adornetto, ${ }^{1}$ Pasquale Molinaro, ${ }^{1}$ Xiao-Fang Li, ${ }^{2}$ Jonathan Lytton, ${ }^{2}$ \\ Gianfranco Di Renzo, ${ }^{1}$ and Lucio Annunziato ${ }^{1}$ \\ ${ }^{1}$ Division of Pharmacology, Department of Neuroscience, School of Medicine, "Federico II" University of Naples, 80131 Naples, Italy, and ²Department of \\ Biochemistry and Molecular Biology, Libin Cardiovascular Institute of Alberta and the Hotchkiss Brain Institute, University of Calgary, Calgary, Alberta, \\ Canada T2N $4 \mathrm{~N} 1$
}

The superfamily of cation/ $\mathrm{Ca}^{2+}$ plasma-membrane exchangers contains two branches, the $\mathrm{K}^{+}$-independent $\mathrm{Na}^{+}-\mathrm{Ca}^{2+}$ exchangers (NCXs) and the $\mathrm{K}^{+}$-dependent $\mathrm{Na}^{+}-\mathrm{Ca}^{2+}$ exchangers (NCKXs), widely expressed in mammals. NCKX2 is the major neuronally expressed isoform among NCKX members. Despite its importance in maintaining $\mathrm{Na}^{+}, \mathrm{Ca}^{2+}$, and $\mathrm{K}^{+}$homeostasis in the CNS, the role of NCKX2 during cerebral ischemia, a condition characterized by an alteration of ionic concentrations, has not yet been investigated. The present study examines NCKX2 role in the development of ischemic brain damage in permanent middle cerebral artery occlusion (pMCA0) and transient middle cerebral artery occlusion. Furthermore, to evaluate the effect of nckx2 ablation on neuronal survival, $n c k x 2-/-$ primary cortical neurons were subjected to oxygen glucose deprivation plus reoxygenation. NCKX2 mRNA and protein expression was evaluated in the ischemic core and surrounding ipsilesional areas, at different time points after pMCA0 in rats. In ischemic core and in periinfarctual area, NCKX2 mRNA and protein expression were downregulated. In addition, NCKX2 knock-down by antisense oligodeoxynucleotide and NCKX2 knock-out by genetic disruption dramatically increased infarct volume. Accordingly, $n c k x 2-/-$ primary cortical neurons displayed a higher vulnerability and a greater $\left[\mathrm{Ca}^{2+}\right]_{\mathrm{i}}$ increase under hypoxic conditions, compared with $n c k \times 2+/+$ neurons. In addition, NCKX currents both in the forward and reverse mode of operation were significantly reduced in $n c k x 2-/-$ neurons compared with $n c k x 2+/+$ cells. Overall, these results indicate that NCKX2 is involved in brain ischemia, and it may represent a new potential target to be investigated in the study of the molecular mechanisms involved in cerebral ischemia.

Key words: NCKX; MCAO; cerebral ischemia; sodium-calcium exchanger; antisense strategy; knock-out

\section{Introduction}

The superfamily of cation/ $\mathrm{Ca}^{2+}$ plasma-membrane exchangers contains two major branches, the $\mathrm{K}^{+}$-independent $\mathrm{Na}^{+}-\mathrm{Ca}^{2+}$ exchangers (NCXs) and the $\mathrm{K}^{+}$-dependent $\mathrm{Na}^{+}-\mathrm{Ca}^{2+}$ exchangers (NCKXs) (Blaustein and Lederer, 1999; Cai and Lytton, 2004). NCX family catalyzes the bidirectional exchange of 3-4 $\mathrm{Na}^{+}$for $1 \mathrm{Ca}^{2+}$ ion (Hilgemann et al., 1991; Blaustein and Lederer, 1999; Annunziato et al., 2004) and is composed of three different gene products, NCX1 (Nicoll et al., 1990), NCX2 (Li et

Received July 15, 2007; revised Dec. 24, 2007; accepted Jan. 6, 2008.

This work was supported by grants from PRIN (Programmi di Ricera di Rilevante Interesse Nazionale) 2006, Regione Campania Genomics for Applied Research, Ricerca Finalizzata Ministero della Salute Legge 502/92 "Geni Vulnerabiltà e di Riparazione DNA," Legge 5/2003, and with the contribution of "Ministero Affari Esteri, Direzione Generale per la Promozione e la Cooperazione Culturale Fondi Italia-Cina Legge 401/1990 2007," all to L.A., and by Canadian Institutes of Health Research Grant FRN15035 to J.L. We thank Dr. Paola Merolla for editorial revision, Dr. Maria Cicale for helping us in NCKX2 probe selection, Dr. Guido laccarino for assisting us in mouse arterial blood pressure measurements, and Dr. Pellegrino Lippiello for his help in performing the electrophysiological experiments.

Correspondence should be addressed to Dr. Lucio Annunziato, Division of Pharmacology, Department of Neuroscience, School of Medicine, "Federico II" University of Naples, Via Pansini 5, 80131 Naples, Italy. E-mail: lannunzi@unina.it.

DOI:10.1523/JNEUROSCI.4912-07.2008

Copyright $\odot 2008$ Society for Neuroscience $\quad$ 0270-6474/08/282053-11\$15.00/0 al., 1994), and NCX3 (Nicoll et al., 1996). NCKX family (Cai and Lytton, 2004) promotes the electrogenic countertransport of 4 $\mathrm{Na}^{+}$ions for $1 \mathrm{Ca}^{2+}$ and $1 \mathrm{~K}^{+}$ion in a bidirectional way (Dong et al., 2001). NCKXs differ from NCXs in their absolute requirement for $\mathrm{K}^{+}$ions and in their lower $\mathrm{Ca}^{2+}$ transport rates (Schwarz and Benzer, 1997; Blaustein and Lederer, 1999). When the sodium gradient is reduced, NCKXs, exploiting the outward $\mathrm{K}^{+}$gradient, extrude $\mathrm{Ca}^{2+}$ more efficiently than NCXs (Lee et al., 2002). Five distinct genes in the NCKX family have been cloned, $n c k x 1$ (Reilander et al., 1992), nckx2 (Tsoi et al., 1998), $n c k \times 3$ (Kraev et al., 2001), $n c k x 4$ (Li et al., 2002), and $n c k x 5$ (Lamason et al., 2005). NCKX2, NCKX3, and NCKX4 are broadly expressed in brain with distinct, often overlapping, regional distributions (Lytton et al., 2002). The expression of NCKX2, the major neuronally expressed isoform (Tsoi et al., 1998; Dong et al., 2001), is limited to cone photoreceptors (Prinsen et al., 2000) and to neurons, where it plays important physiological roles (Tsoi et al., 1998; Li et al., 2006).

Importantly, in axon terminals, when $\left[\mathrm{Ca}^{2+}\right]_{\mathrm{i}}$ is $>500 \mathrm{nM}$, $>60 \%$ of calcium extrusion is mediated by sodium-calcium exchangers, of which $90 \%$ is attributable to NCKX activity (Lee et 
al., 2002; Kim et al., 2003, 2005). Furthermore, nckx2 knock-out resulted in deficits in neuronal $\mathrm{Ca}^{2+}$ transport, in hippocampal synaptic plasticity, and in motor learning and memory functions (Li et al., 2006).

Despite NCKX2 importance in $\mathrm{Ca}^{2+}$ homeostasis and neuronal function in CNS, its role in stroke, a pathological condition characterized by an alteration of $\mathrm{Na}^{+}, \mathrm{K}^{+}$, and $\mathrm{Ca}^{2+}$ intraneuronal concentrations (Lipton, 1999), has not yet been investigated. Moreover, NCKX2 is highly expressed in cerebral cortex, striatum, and hippocampus, regions involved in the ischemic insult consequent to middle cerebral artery occlusion (MCAO) in human, primates, and rodents.

In the present report, to assess NCKX2 role in cerebral ischemia, we first analyzed NCKX2 mRNA and protein expression in the ischemic core and in the ipsilesional nonischemic areas in rats at different time intervals after permanent MCAO (pMCAO). Then, NCKX2 role in the development of ischemic damage was assessed both in rats, in which NCKX2 expression was knockeddown by a specific antisense oligodeoxynucleotide (ODN), and in mice, in which $n c k x 2$ gene was knocked-out. Furthermore, to establish mechanistic insights on how the lack of the NCKX2 could affect neuronal survival in stroke, we have reproduced an in vitro model mimicking cerebral ischemia, by exposing primary neuronal cultures from $n c k x 2-/-$ mice to oxygen-glucose deprivation (OGD) followed by reoxygenation. In this experimental model, intracellular calcium concentrations $\left(\left[\mathrm{Ca}^{2+}\right]_{\mathrm{i}}\right)$ were detected. Finally, NCKX currents $\left(I_{\mathrm{NCKX}}\right)$, in forward and reverse mode of operation, were recorded by means of patch-clamp technique in $n c k \times 2-/-$ cortical neurons exposed to hypoxia.

\section{Materials and Methods \\ Experimental groups}

Male Sprague Dawley rats (Charles River, Calco, Italy) weighing 250-270 $\mathrm{g}$ and male C57BL/6 nck $x 2+/+$ (Charles River) and $n c k \times 2-/-$ mice of the same age ( $8-10$ weeks) and weight $(22-25 \mathrm{~g})$ were housed in the same diurnal lighting conditions ( $12 \mathrm{~h}$ darkness and $12 \mathrm{~h}$ light). Experiments were performed on rats and mice according to the international guidelines for animal research. The researchers who performed surgery, evaluation of ischemic volume and focal and general neurological scores, genotyping of the mice, and treatments of the rats and neuronal cultures were blinded toward the experimental schedule. The experimental protocol was approved by the Animal Care Committee of the "Federico II" University of Naples.

\section{Surgical procedures}

Osmotic minipump implantation. Sprague Dawley rats, anesthetized with chloral hydrate $(400 \mathrm{mg} / \mathrm{kg}$, i.p.), were put on a stereotaxic frame. An Alzet (Cupertino, CA) osmotic minipump (model 1003D; delivery rate, 1 $\mu \mathrm{l} / \mathrm{h}$ ) was inserted into a subcutaneous pouch under the skin of the neck and was connected via a plastic catheter to the brain infusion cannula placed into the right lateral ventricle. Twenty-four hours after cannula implantation, pMCAO was induced as previously described (Pignataro et al., 2004b). Antisense, scramble, and sense oligodeoxynucleotides (250 $\mu \mathrm{M}, 140 \mu \mathrm{g} / \mathrm{kg}$ ), when infused intracerebroventricularly, did not affect body temperature.

pMCAO model. All rats were anesthetized intraperitoneally with chloral hydrate ( $400 \mathrm{mg} / \mathrm{kg}$ body weight). A $2 \mathrm{~cm}$ incision was made vertically between the orbit and the ear, so as to create a small window just over the visibly identified middle cerebral artery (MCA). The left MCA was electrocauterized by means of a bipolar electrocauterizer (Diatermo MB122; G.I.M.A., Milan, Italy) as close as possible to its origin, near the circle of Willis (Tamura et al., 1981). The body temperature was continuously monitored with a rectal probe (Homeothermic Blanket System; Harvard Apparatus, Holliston, MA) and maintained at $37 \pm 0.5^{\circ} \mathrm{C}$ until the end of the surgical procedure.

Transient middle cerebral artery occlusion model. C57BL/6 nckx2+/+
Table 1. Physiological data (CBF, blood gases, blood pressure) for $n c k x 2+/+$ and nckx2-/- mice

\begin{tabular}{llc}
\hline Genotype & $n c k \times 2+/+$ & $n c k \times 2-/-$ \\
\hline $\mathrm{pH}$ & $7.30 \pm 0.06$ & $7.22 \pm 0.06$ \\
$\mathrm{pO}_{2}$ & $97.8 \pm 3.8$ & $101.2 \pm 2.01$ \\
$\mathrm{pCO}_{2}$ & $38.9 \pm 0.67$ & $39.7 \pm 2.6$ \\
$\mathrm{CBF}$ reduction (\%) & $80.6 \pm 1.3$ & $81.8 \pm 2.9$ \\
Mean arterial blood pressure & $85.7 \pm 3.1$ & $84.1 \pm 0.8$ \\
\hline
\end{tabular}

and $n c k \times 2-/-$ mice were subjected to transient middle cerebral artery occlusion (tMCAO) as previously described (Longa et al., 1989). Under an operating stereomicroscope (Nikon SMZ800; Nikon Instruments, Florence, Italy) the right carotid bifurcation was carefully exposed and the external carotid artery (ECA) coagulated distal to the bifurcation. A 5-0 nylon filament, with its tip rounded by heating near a flame, was inserted through the ECA stump and gently advanced $(11 \mathrm{~mm})$ into the right internal carotid artery until it blocked the origin of the MCA. The surgical wound was closed and the filament left in place. After $60 \mathrm{~min}$ of MCA occlusion, the filament was gently withdrawn to restore blood flow. Animals were allowed to recover from anesthesia at room temperature.

Monitoring of arterial blood pressure, CBF, and blood gas concentration. Arterial blood pressure was measured through a catheter inserted into the common carotid artery, connected to solid-state pressure transducers (Power lab system; ADI instruments, Castle Hill, Australia) and analyzed by CHART Windows software. Mean arterial blood pressure values, ranging from 82 to $86 \mathrm{mmHg}$, did not differ significantly between $n c k \times 2+/+$ and $n c k \times 2-/-$ mice (Table 1$)$. Cerebral blood flow (CBF) was monitored in the cerebral cortex ipsilesional to the occluded MCA with a laser-Doppler flowmeter (Periflux system, 5000) in all mice and rats used in ischemia experiments (Pignataro et al., 2004b). LaserDoppler perfusion was monitored, in mice, throughout the $1 \mathrm{~h}$ occlusion period and the first $30 \mathrm{~min}$ of reperfusion, and in rats, during all the surgical procedure until $30 \mathrm{~min}$ after the occlusion to verify the $\mathrm{CBF}$ reduction after MCA electrocauterization. Only rats and mice that, after $\mathrm{MCAO}$, reached at least $70 \%$ of $\mathrm{CBF}$ reduction were included in the experimental groups (Pignataro et al., 2007). CBF reduction induced by MCAO did not differ significantly between $n c k \times 2+/+$ and $n c k \times 2-/-$ mice (Table 1). In some of the experimental and control animals, a catheter was inserted into the common carotid artery to measure arterial blood gases with a blood gas analyzer (Rapid Lab 860; Chiron Diagnostic, Emeryville, $\mathrm{CA}$ ). $\mathrm{PaO}_{2}, \mathrm{PaCO}_{2}$, and $\mathrm{pH}$ mean values did not change between $n c k \times 2$ knock-out and wild-type mice (Table 1).

Cerebrovascular anatomy evaluation of nck $\times 2+/+$ and nck $\times 2-1-$ mice. Cerebral macrovascular morphology was assessed by examining the major cerebral blood vessels of the circle of Willis after transcardial perfusion of $n c k \times 2+/+$ and $n c k \times 2-/-$ mice with a solution containing gelatin and waterproof Pelikan Ink (9:1), according to the methodology described by Paxinos and Franklin and other authors to evaluate cerebrovascular anatomy (Huang et al., 1994; Scremin, 1995; Paxinos and Franklin, 2000; Lo et al., 2007).

After injection, the entire head was fixed in $10 \%$ formalin overnight before brain removal, to prevent deformation of the brain. The dorsal aspect of the brain was acquired using a macro objective to visualize the line of anastomosis between the anterior cerebral artery (ACA) and MCA. To this aim, we calculated the ratio between the area medial to the line of anastomoses and the total dorsal area of the hemisphere (Maeda et al., 1998). Moreover, the posterior communicating arteries (PComAs) and the basilar artery (BA) were visualized with a $10 \times$ objective and imaged on a computer using a high-resolution digital camera to analyze changes in the diameter of the PComAs and BA (Kitagawa et al., 1998). The data were expressed as the ratio between the calculated diameter of PComAs and BA. Image analysis was made using the NIH Image 1.59 software (National Institutes of Health, Bethesda, MD). All values are given as mean \pm SEM.

After this procedure, to analyze the cerebral microvascular density, the brains were cryopreserved and later serially sectioned on a cryostat at $-20^{\circ} \mathrm{C}$. Microvascular density was assessed in the frontoparietal cortex 
Table 2. In situ hybridization NCKX2 antisense probe information

\begin{tabular}{|c|c|c|c|c|c|}
\hline Probe & GenBank accession number & Position & $5^{\prime}$-oligonucleotide sequence-3' & Length & $\%$ Identity/gaps ${ }^{a}$ \\
\hline \multirow[t]{2}{*}{ NCKX2 } & AF021923 & $2978-3026$ & AAACAAGACAGCCTAACCCTCAA & $48 \mathrm{bp}$ & NCKX3:58/0 \\
\hline & & & CAGATGCCGCACCCTCCCCGCCCCC & & NCKX4:52/0 \\
\hline
\end{tabular}

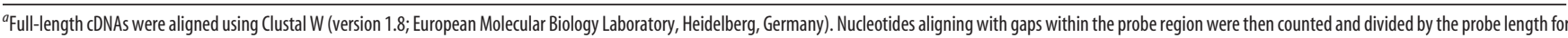
percentage.

and in the striatum in five sets of three sections ( $25 \mu \mathrm{m}$ thick) cut $150 \mu \mathrm{m}$ apart corresponding approximately to plates $12-16$ in a mouse brain atlas (Paxinos and Franklin, 2000). Composite images spanning the full depth of the frontoparietal cortex and the entire area of the striatum were obtained using an Axioskop 20 microscope (Zeiss, Oberkochen, Germany) with motorized XYZ stage (Prior, Rockland, MA) equipped with a high-resolution CCD camera. Images were acquired and analyzed using the MCID Elite software to determine the number of Ink-positive capillary profiles that were $<10 \mu \mathrm{m}$ in diameter. Cortical and striatal capillary densities were expressed as the mean \pm SEM of 15 composite images obtained from each brain. Data are expressed as number of capillaries per $\mathrm{mm}^{2}$ in $25-\mu \mathrm{m}$-thick slices.

\section{$m R N A$ expression analysis by real-time PCR}

The ischemic core and the area surrounding the ischemic core, dissected from the ipsilesional hemisphere of sham-operated and ischemic rats at 6,9 , and $72 \mathrm{~h}$ after surgery, were frozen on dry ice. Brain samples were ground into powered dry ice, then GITC solution (4 M guanidinium isothiocyanate, $25 \mathrm{~mm} \mathrm{Na}$ citrate, $0.5 \%$ Sarkosyl, and $0.7 \%$ $\beta$-mercaptoethanol) was added. Total RNA was extracted and purified as previously described (Matrone et al., 2004). For reverse transcription, 2.0 $\mu \mathrm{g}$ of each extracted RNA was digested with DNase and reverse transcribed using iScript cDNA synthesis kit (Bio-Rad, Mississauga, Ontario, Canada). All data were normalized to glyceraldehyde-3-phosphate dehydrogenase (GAPDH) mRNA levels and expressed as percentage of the mRNA levels detected in sham-operated animals. Sequences of the primers used were the following: NCKX2 193 nt forward (F) (382-401), CTGGAGGAGCGAAGGAAAGG; reverse (R) (555-576), TGTGAAAGTTCTGGGGCTGAC; GAPDH 232 nt F (492-513), CAACTTTGGCATCGTGGAAGGG; R (700-723), CAACGGATACATTGGGGGTAGG.

\section{Western blot analysis}

Total protein extracts from dissected areas of ischemic and nonischemic rat brains were obtained and analyzed as previously described (Matrone et al., 2004) at 3, 6, 24, and $72 \mathrm{~h}$ after pMCAO. One group of rats received the calpain inhibitor calpeptin ( $1 \mathrm{mg} / \mathrm{kg}$; EMD Biosciences, San Diego, CA) $1 \mathrm{~h}$ before pMCAO induction and was killed $3 \mathrm{~h}$ after ischemia onset to analyze NCKX2 protein expression in the ischemic core and in the remaining ipsilateral nonischemic area.

Nitrocellulose membranes were incubated with anti-NCKX2 antibody (1:100 dilution; polyclonal rabbit antibody; Vinci Biochem, Vinci, Italy). In mice, a polyclonal anti-NCKX2 antibody (1:500 dilution) produced by our research group (Department of Biochemistry and Molecular Biology, University of Calgary) was used. The nitrocellulose membranes were washed with $0.1 \%$ Tween 20 and incubated with secondary antibodies for $1 \mathrm{~h}$ (GE Healthcare, Little Chalfont, UK). Immunoreactive bands were detected with the ECL (GE Healthcare). The optical density of the bands, normalized with that of $\beta$-actin (Sigma, St. Louis, MO), was determined by Chemi-Doc Imaging System (Bio-Rad).

\section{In situ hybridization}

Tissue preparation for in situ hybridization. Rats were killed $24 \mathrm{~h}$ after the onset of the pMCAO. The brains, rapidly removed and quickly frozen on powdered dry ice, were stored at $-70^{\circ} \mathrm{C}$ before sectioning. Serial coronal sections of $12 \mu \mathrm{m}$ were cut on a cryostat (Cryo-Star HM $560 \mathrm{MV}$; Microm International, Walldorf, Germany) at the following levels: medial prefrontal cortex $(\mathrm{PFC})$, anterior caudate-putamen $(\mathrm{CPu})$, posterior $\mathrm{CPu}$, and dorsal hippocampus. All sections corresponded approximately to the bregma levels of +3.20 and $-0.30 \mathrm{~mm}$, respectively (Paxinos and Watson, 1998). Each slide contained three adjacent sections of each animal. To select identical anatomical levels in control, sham-operated, and ischemic sections, thionin-stained reference slides were used. Sections were thaw mounted onto gelatin-coated slides and stored at $-70^{\circ} \mathrm{C}$ for subsequent analysis.

Oligonucleotide probes and radiolabeling. The antisense oligonucleotide probes for labeling NCKX2 transcripts (MWG Biotech, Florence, Italy) are listed in Table 2 . To maximize probe specificity, the probe sequences were chosen in regions of low nucleotide homology among the different NCKX isoforms. In addition, to maximize the probe stability, those sequences containing guanine and cytosine levels close to $60 \%$ and a very low number of oligo duplexes or hairpin stem formations were selected. Hence the sequences were tested for specificity through a BLAST search (http://www.ncbi.nlm.nih.gov/blast/Blast.cgi). NCKX2 probe was a 48 b oligodeoxyribonucleotide (Table 2) complementary to bases 2978-3026 of the rat brain NCKX2 mRNA (GenBank accession number AF021923). In our in situ hybridization experiments, the NCKX2 probe also recognized the unique splice variant described for this gene in rat brain (Tsoi et al., 1998). Radiolabeling of oligonucleotides probes was performed as previously described (Boscia et al., 2006).

Autoradiography. Sections from sham-operated and ischemic rats were processed for radioactive in situ hybridization as previously described (Boscia et al., 2006). To detect NCKX2 mRNA, the sections were first dried and then exposed to Kodak-Biomax MR Autoradiographic film (GE Healthcare) for 1 week. The autoradiographic signal yielded by the probes was compared with the results obtained with nonradioactive in situ hybridization (Tsoi et al., 1998) The specificity of each probe for the three NCKX isoforms, NCKX2, NCKX3, and NCKX4, was further tested by a control experiment using the corresponding sense oligo (negative control) (data not shown).

Image analysis. Image analysis was performed as previously described (Boscia et al., 2006). Within the PFC region, at the bregma level of +3.20 $\mathrm{mm}$, three regions of interest (ROIs) were defined: PFC1 was placed in the center of the infarct area (core region); PFC2 was equivalent to the periinfarct area; and PFC3 included the cingulate cortex (see Fig. 2 A). At the bregma level of $-0.30 \mathrm{~mm}$, three ROIs were chosen in the cortex (CTX1, CTX2, and CTX3) and one in the striatum (CPu) (see Fig. 2G). CTX3 was located outside the infarct area; CTX2 was located in the periinfarct zone; and CTX1 was located within the core lesion area.

Data processing. Measurements of transmittance within ROIs were converted into relative disintegration per minute (relative dpm) using a calibration curve based on ${ }^{14} \mathrm{C}$ standard scale coexposed with the sections, and cross-calibrated with ${ }^{35} \mathrm{~S}$-brain paste standards containing known amounts of radioactivity. For this purpose a "best-fit" thirddegree polynomial was used, as already described (Boscia et al., 2006). Quantitative comparisons among different experimental groups were performed using images from hybridized sections exposed on the same $\mathrm{x}$-ray film sheet. For each individual section, the value of each ROI contralateral to the ischemic side was subtracted from that of the corresponding ipsilesional side. Differences were calculated in the control, sham-operated, and pMCAO-bearing animals. Measurements from 2-3 consecutive sections of each animal were averaged. The data calculated in the control, sham-operated, and ischemic animals were averaged and processed for statistical analysis. Data were analyzed by means of unpaired two-tailed Student's $t$ test. Because no statistically significant difference was found between control and sham-operated animals, the data are presented as a comparison of pMCAO-bearing animals and shamoperated rats.

\section{NeuN immunohistochemistry}

Sham-operated and ischemic slices kept on chromalum-gelatin slide were fixed at room temperature in $4 \%(\mathrm{w} / \mathrm{v})$ paraformaldehyde in PBS for $30 \mathrm{~min}$. Briefly, slices were washed four times in PBS, treated with $1 \%$ 


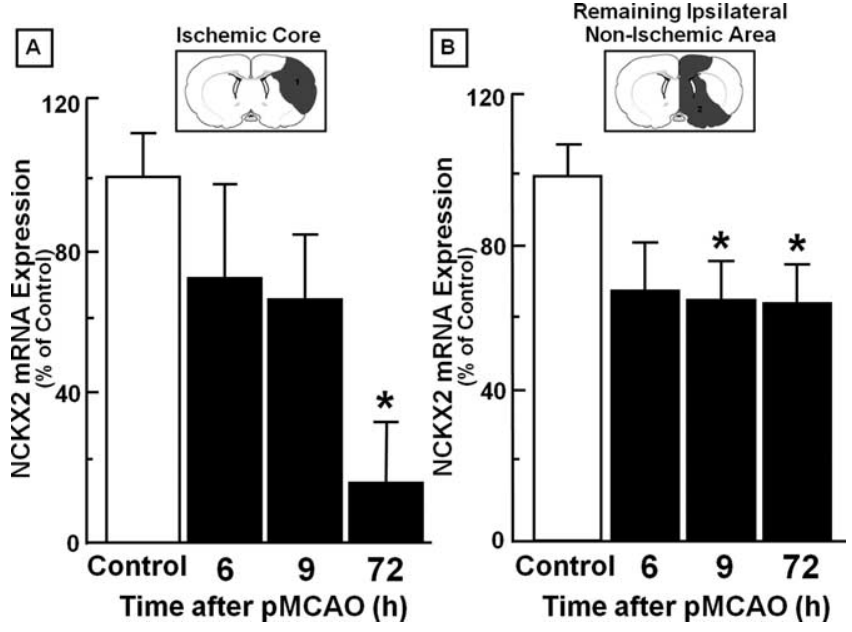

Figure 1. Time course of NCKX2 mRNA expression after PMCAO in the ischemic core and in the remaining ipsilateral nonischemic area. $\boldsymbol{A}, \boldsymbol{B}$, Real-time PCR of NCKX2 mRNA expression in the ischemic core $(\boldsymbol{A})$ and in the remaining ipsilateral nonischemic area $(\boldsymbol{B})$ are represented. Data were normalized on the basis of GAPDH levels and expressed as a percentage of shamoperated controls, taken as $100 \%$. Values represent means $\pm \operatorname{SEM}(n=7) .{ }^{*} p<0.05$, compared with control animals.

(v/v) hydrogen peroxide $\left(\mathrm{H}_{2} \mathrm{O}_{2}\right)$ in PBS for 5 min, washed three times in PBS, and, finally, preincubated in PBS containing 3\% (w/v) bovine serum albumin (Sigma, Milan, Italy) and $0.1 \%$ (v/v) Triton-X (Bio-Rad). Then, the sections were incubated with the primary antibody anti-NeuN (1:2000; Millipore, Vimodrone, Italy) at $4^{\circ} \mathrm{C}$ overnight, washed six times in PBS, and finally incubated with the biotinylated secondary antibody (1:200; horse anti-mouse IgG; Vector Laboratories, Burlingame, CA) for $2 \mathrm{~h}$ at room temperature. Next, they were washed in PBS and processed with the Elite Vectastain avidin-biotin kit (1:300; 1, 5 h; Vector Laboratories). The peroxidase reaction was developed by $3-3^{\prime}-$ diaminobenzidine tetrahydrochloride (Sigma) as a chromogen. After the final wash, sections were dehydrated and coverslipped. Slices were acquired with a CCD digital camera (C-5985; Hamamatsu Photonics, Milan, Italy) and Image Pro-Plus software (Media Cybernetics, Silver Spring, MD).

\section{Antisense oligodeoxynucleotide design}

A chimeric phosphorothioated antisense ODN (AS-ODN) (Primm, Milan, Italy) was designed to target the area near the start region. NCKX2 antisense was a 20 b oligodeoxynucleotide, complementary to bases $102-$ 121 of the rat brain NCKX2 mRNA (GenBank accession number AF021923). AS-ODN sequence is the following (underlined bases are phosphorothioated): AS-NCKX2 (+102/+121): 5'-CCAATGACTCGAATTAGCTT-3'.

Phosphorothioated ODNs display an increased stability and are more easily diffused into the brain when they are intracerebroventricularly infused (Yaida and Nowak, 1995). The AS-ODN was designed on a region of NCKX2 sequence with low homology to the sequence of the other NCKX and NCX isoforms, as resulted from the alignment of NCKX2 with NCKX and NCX sequences. Hence, AS- and scramble ODN sequences were tested for specificity through a BLAST search (http://www.ncbi.nlm.nih.gov/blast/Blast.cgi).

Antisense (CCAATGACTCGAATTAGCTT), sense (5'-AAGCTAATTCGAGTCATTGG-3'), and scramble (TGCACACTTACAACGTAGTT) NCKX2 ODNs were continuously infused in rats $(250 \mu \mathrm{M}, 140$ $\mu \mathrm{g} / \mathrm{kg}$, i.c.v.) with osmotic minipumps for $48 \mathrm{~h}$, starting $24 \mathrm{~h}$ before pMCAO induction (Pignataro et al., 2004b).

Evaluation of AS-ODN efficacy in vitro and in vivo AS-ODN efficacy was evaluated on NGF-differentiated rat pheochromocytoma cells (PC12 cells) at the concentration of $3 \mu \mathrm{M}$. PC12 cells were grown as previously described (Pannaccione et al., 2005).

The AS-ODN entrance into the cells was enhanced by Lipofectamine
2000 (Invitrogen, Milan, Italy). Western blot analysis was performed 12 and $24 \mathrm{~h}$ after cell transfection with the antisense. AS-ODN efficacy was tested also in vivo by measuring NCKX2 expression by Western blot in male rats treated with AS-ODN (140 $\mu \mathrm{g} / \mathrm{kg}$, i.c.v.) infused through an osmotic minipump for $24 \mathrm{~h}$.

Evaluation of the ischemic volume in rats treated with AS-ODN

To evaluate whether AS-ODN could affect the ischemic volume in rats, the antisense was injected continuously for $48 \mathrm{~h}$, starting $24 \mathrm{~h}$ before pMCAO induction. Then, the animals were decapitated $24 \mathrm{~h}$ after ischemia onset, a time when the extension of infarct was maximal (Tortiglione et al., 2002). The infarct area and the total volume of the lesion were evaluated with 2,3,5-triphenyl tetrazolium chloride staining and calculated as previously described (Tortiglione et al., 2002). The total infarct volume was expressed as a percentage of the volume of the ipsilesional hemisphere (Pignataro et al., 2004a).

\section{Evaluation of the ischemic volume and of neurological deficits in} $\mathrm{nckx} 2+1+C 57 B L / 6$ wild-type mice and $\mathrm{nckx} 2-1-$ mice $n c k \times 2+/+\mathrm{C} 57 \mathrm{BL} / 6$ and $n c k \times 2-/-$ male mice (Li et al., 2006), subjected to $1 \mathrm{~h}$ of tMCAO, were decapitated $24 \mathrm{~h}$ after ischemia onset. The infarct area and the total volume of the lesion were evaluated as previously described (Pignataro et al., 2004a). Twenty-four hours postischemia, each neurological function was scored according to two scales: a general neurological scale (general score, $0-28$ ) and a focal neurological scale (focal score, 0-28) (Clark et al., 1997).

\section{Primary cortical neurons}

Cortical neurons were prepared from brains of 14-d-old mouse embryos (Charles River), plated on coverslips, and cultured in MEM/F12 (Invitrogen) containing glucose, $5 \%$ of deactivated fetal bovine serum and $5 \%$ horse serum (Invitrogen), glutamine (2 $\mathrm{mm}$ ), penicillin (50 $\mathrm{U} / \mathrm{ml})$, and streptomycin (50 $\mu \mathrm{g} / \mathrm{ml})$. Cytosine- $\beta$-D-arabinofuranoside $(10 \mu \mathrm{M})$ was added within $5 \mathrm{~d}$ of plating to prevent the growth of non-neuronal cells. Neurons were cultured at $37^{\circ} \mathrm{C}$ in a humidified $5 \% \mathrm{CO}_{2}$ atmosphere and used after $7-10 \mathrm{~d}$ in vitro (DIV) (Scorziello et al., 2007). Hypoxic conditions were induced by exposing cortical neurons to oxygen- and glucose-free medium in a humidified atmosphere containing 95\% nitrogen and 5\% $\mathrm{CO}_{2}$ (Scorziello et al., 2007). In primary cortical neurons, cell injury was assessed after $3 \mathrm{~h}$ of OGD followed by $21 \mathrm{~h}$ of reoxygenation. Propidium iodide(PI; $7 \mu \mathrm{M}$ ) and fluorescein diacetate- (FDA; $36 \mu \mathrm{M}$ ) positive cells were counted in three representative high-power fields of independent cultures, and cell death was determined by the ratio of the number of PI-positive cells/PI+FDA-stained-positive cells.

\section{$\left[\mathrm{Ca}^{2+}\right]_{i}$ measurement}

$\left[\mathrm{Ca}^{2+}\right]_{\mathrm{i}}$ was measured by single-cell computer-assisted videoimaging (Secondo et al., 2007). Briefly, cortical neurons, grown on glass coverslips, in control conditions and after exposure to $3 \mathrm{~h}$ of OGD plus 4, 6, and $21 \mathrm{~h}$ of reoxygenation, were loaded with $6 \mu \mathrm{M}$ fura- 2 AM (EMD Biosciences) for $30 \mathrm{~min}$ at $37^{\circ} \mathrm{C}$. At the end of the fura- $2 \mathrm{AM}$ loading period, the coverslips were placed into a perfusion chamber (Medical Systems, Greenvale, NY) mounted onto a Zeiss Axiovert 200 microscope equipped with a FLUAR $40 \times$ oil objective lens. The experiments were performed with a digital imaging system composed of MicroMax 512BFT cooled CCD camera (Princeton Instruments, Trenton, NJ), LAMBDA 10-2 filter wheeler (Sutter Instruments, Novato, CA), and Meta-Morph/MetaFluor Imaging System software (Universal Imaging, West Chester, PA). After loading, cells were alternatively illuminated at wavelengths of 340 and $380 \mathrm{~nm}$ by a xenon lamp. The emitted light was passed through a $512 \mathrm{~nm}$ barrier filter. Fura-2 AM fluorescence intensity was measured every $3 \mathrm{~s}$. Ratiometric values were automatically converted by the software into $\left[\mathrm{Ca}^{2+}\right]_{\mathrm{i}}$ using a preloaded calibration curve obtained in preliminary experiments as previously reported (Grynkiewicz et al., 1985).

\section{Electrophysiology}

$I_{\mathrm{NCKX}}$ was recorded from primary $n c k \times 2+/+$ and $n c k \times 2-/-$ cortical neurons by the patch-clamp technique in whole-cell configuration. 

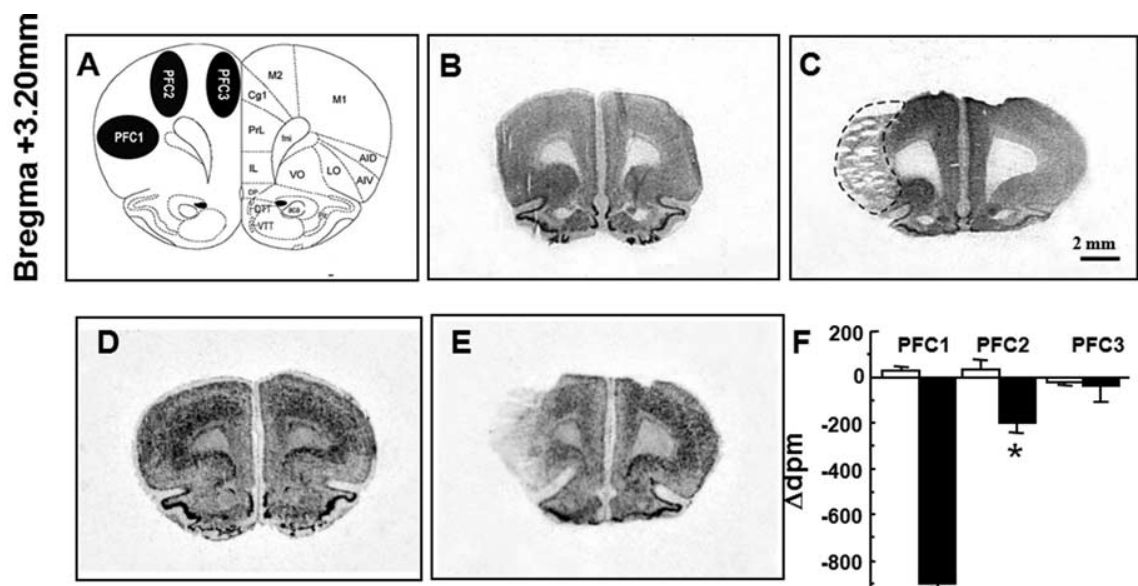

Sham (24h)
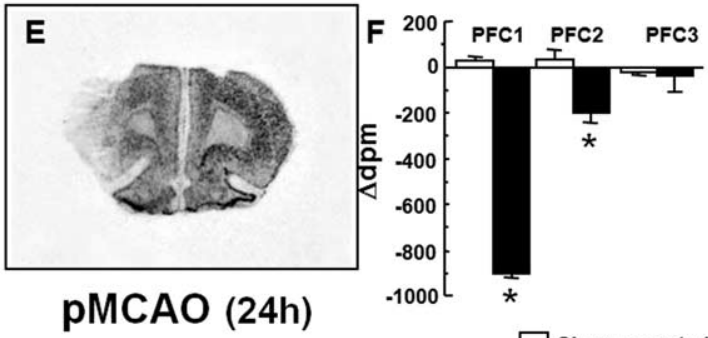

$\square$ Sham-operated PMCAO
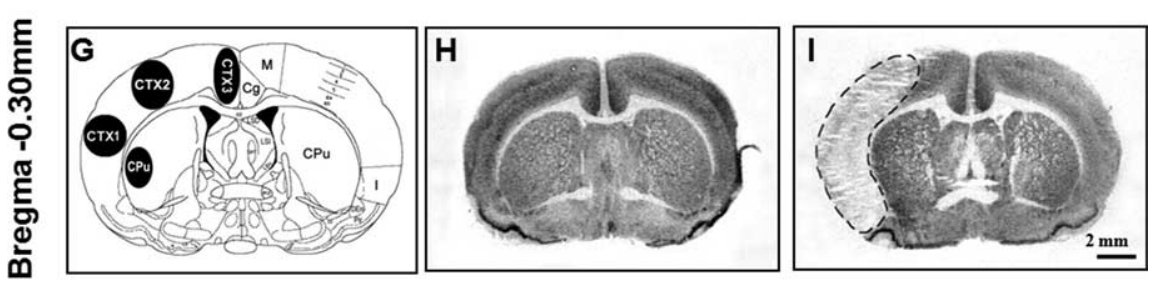

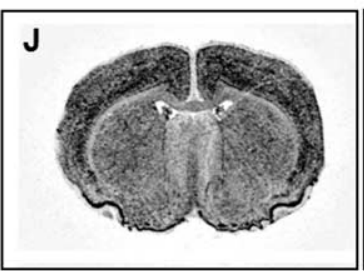

Sham (24h)

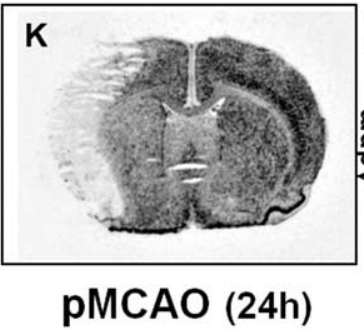

PMCAO (24h)

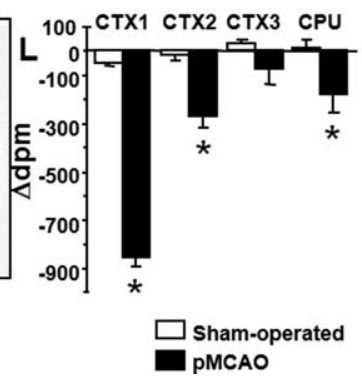

Figure 2. Radioactive in situ hybridization of NCKX2 transcript in the cerebral cortex and caudate-putamen of sham-operated and ischemic animals $24 \mathrm{~h}$ after sham surgery or pMCA0. A schematic diagram of regions of interest at coronal bregma levels of $+3.20 \mathrm{~mm}$ and of $-0.30 \mathrm{~mm}$ are shown in $\boldsymbol{A}$ and $\boldsymbol{G}$. Representative brain NeuN-immunohistochemistry-processed sections deriving from sham-operated and pMCA0-bearing rats are shown in $\boldsymbol{B}$ and $\boldsymbol{C}$ (bregma level, $+3.20 \mathrm{~mm}$ ) and $\boldsymbol{H}$ and $\boldsymbol{I}$ (bregma level, $-0.30 \mathrm{~mm}$ ), respectively. $\boldsymbol{D}$ and $\boldsymbol{J}$ and $\boldsymbol{E}$ and $\boldsymbol{K}$ represent the in situ hybridization autoradiographic film images obtained from sham-operated and ischemic brain sections with NCKX2 antisense probe, respectively. mRNA levels expressed as $\Delta \mathrm{dpm} \pm$ SEM and presented for each region of interest analyzed, with white columns for sham-operated rats and black columns for pMCAO rats, are shown in $\boldsymbol{F}$ and $\boldsymbol{L}$. $\Delta \mathrm{dpm}$ indicates the difference between the dpm value of each region of interest ipsilateral to the ischemic side and that of the contralateral corresponding side. ${ }^{*} p<0.05$ versus respective values in sham-operated groups. aca, Anterior commissure, anterior part; AID, agranular insular cortex, dorsal part; AIV, agranular insular cortex, ventral part; Cc, corpus callosum; Cg, cingulate cortex; CPu, caudate-putamen; DP, dorsal peduncular cortex; DTT, dorsal tenia tecta; fmi, forceps minor of the corpus callosum; IL, infralimbic cortex; I, insular cortex; LO, lateral orbital cortex; M, motor cortex; M1, primary motor cortex; M2, secondary motor cortex; Pir, piriform cortex; PrL, prelimbic cortex; V0, ventral orbital cortex; VTT, ventral tenia tecta. Scale bars: $\boldsymbol{C}($ for $\boldsymbol{B}, \boldsymbol{C}), \boldsymbol{I}($ for $\boldsymbol{H}, \boldsymbol{I}), 2 \mathrm{~mm}$.

Currents were filtered at $5 \mathrm{kHz}$ and digitized using a Digidata $1322 \mathrm{~A}$ interface (Molecular Devices, Sunnyvale, CA). Data were acquired and analyzed using the pClamp software (version 9.0; Molecular Devices). Reverse and forward $I_{\mathrm{NCKX}}$ were recorded using a holding potential of $0 \mathrm{mV}$. The $I_{\mathrm{NCKX}}$ was recorded, according to Dong et al. (2001), starting from a holding potential of $0 \mathrm{mV}$ to a short-step depolarization at $+80 \mathrm{mV}(60 \mathrm{~ms})$. Then, a descending voltage ramp from $+80 \mathrm{mV}$ to $-80 \mathrm{mV}$ was applied. The current recorded in the descending portion of the ramp (from $+80 \mathrm{mV}$ to $-80 \mathrm{mV}$ ) was used to plot the current-voltage $(I-V)$ relation curve. The magnitude of $I_{\mathrm{NCKX}}$ was measured at the end of $+80 \mathrm{mV}$ (reverse mode) and at the end of $-80 \mathrm{mV}$ (forward mode), respectively. Current recordings in control conditions, in which $I_{\mathrm{NCKX}}$ were not detectable, were obtained by perfusing cortical neurons with $\mathrm{Na}^{+}-, \mathrm{Ca}^{2+}$-, and $\mathrm{K}^{+}$-free bath solution containing the following (in $\mathrm{mm}$ ): $130 \mathrm{LiCl}, 1$ $\mathrm{MgCl}_{2}, 10$ D-glucose, $10 \mathrm{HEPES}, 0.5$ EGTA, 20 tetraethylammonium (TEA), $10 \mu \mathrm{M}$ nimodipine, and $50 \mathrm{~nm}$ tetrodotoxin (TTX), $\mathrm{pH}$ 7.4. TTX, nimodipine, and TEA were used to block TEA-sensitive $\mathrm{K}^{+}$, TTX-sensitive $\mathrm{Na}^{+}$, and L-type $\mathrm{Ca}^{2+}$ currents. To record both reverse and forward $I_{\mathrm{NCKX}}$, the external solution was varied by replacing $130 \mathrm{~mm} \mathrm{LiCl}$ with $80 \mathrm{~mm} \mathrm{NaCl}$ and $50 \mathrm{~mm} \mathrm{KCl}$, and adding $1 \mathrm{~mm}$ $\mathrm{CaCl}_{2}$. The dialyzing pipette solution contained the following (mM): $18 \mathrm{NaCl}, 100$ potassium gluconate, 20 TEA, 1 MgATP, 10 EGTA, $6.4 \mathrm{CaCl}_{2}, 10 \mathrm{D}$-glucose, and 10 HEPES, pH 7.2. Free $\left[\mathrm{Ca}^{2+}\right]$ under these experimental conditions was $\sim 0.3 \mu \mathrm{M}$. $I_{\mathrm{NCKX}}$ was isolated by digital subtraction of currents elicited under conditions where NCKXs were inactive (bath perfusion with $\mathrm{Li}^{+}$and lacking $\mathrm{Na}^{+}, \mathrm{Ca}^{2+}$, and $\mathrm{K}^{+}$ions) from currents elicited under conditions compatible with NCKXs function (bath perfusion with a solution containing $\mathrm{Na}^{+}, \mathrm{K}^{+}$, and $\mathrm{Ca}^{2+}$ ions). In these experimental conditions, the reversal potential for $I_{\mathrm{NCKX}}$ was estimated to be -10 $\mathrm{mV}$, which was much greater than the reversal potential reported for $I_{\mathrm{NCX}}(-40 \mathrm{mV})$ (Hilgemann et al., 1991). This large difference between the reversal potential of $I_{\mathrm{NCKX}}$ estimated in the present study and that reported for $I_{\mathrm{NCX}}$, together with the inhibitory effect on NCX currents exerted by the high external $\mathrm{K}^{+}$concentrations (Zhang and Hancox, 2003) used in the present study, allows us to exclude a significant $I_{\mathrm{NCX}}$ contamination of the recorded current. This aspect was further supported by the decrease in the current magnitude observed in $n c k \times 2-/-$ primary cortical neurons compared with $n c k \times 2+/+$ cells.

Possible changes in cell size occurring after specific treatments were calculated by monitoring the capacitance of each cell membrane, which is directly related to membrane surface area, and by expressing the current amplitude data as current densities $(\mathrm{pA} / \mathrm{pF})$. Capacitive currents were estimated from the decay of capacitative transient induced by $5 \mathrm{mV}$ depolarizing pulses from a holding potential of -80 $\mathrm{mV}$ and acquired at a sampling rate of $50 \mathrm{kHz}$. The capacitance of the membrane was calculated according to the following equation: $C_{\mathrm{m}}$ $=\tau_{\mathrm{c}} \times I_{\mathrm{o}} / \Delta E_{\mathrm{m}}\left(1-I_{\infty} / I_{\mathrm{o}}\right)$, where $C_{\mathrm{m}}$ is membrane capacitance, $\tau_{\mathrm{c}}$ is the time constant of the membrane capacitance, $I_{o}$ is the maximum capacitance current value, $\Delta E_{\mathrm{m}}$ is the amplitude of the voltage step, and $I_{\infty}$ is the amplitude of the steady-state current.

\section{Statistical analysis}

Values are expressed as means \pm SEM. Statistical analysis was performed with ANOVA followed by Newman-Keuls test. Neurological deficits data were analyzed using the nonparametric Kruskal-Wallis test. Statistical significance was accepted at the 95\% confidence level $(p<0.05)$. Values are expressed as means \pm SEM. 


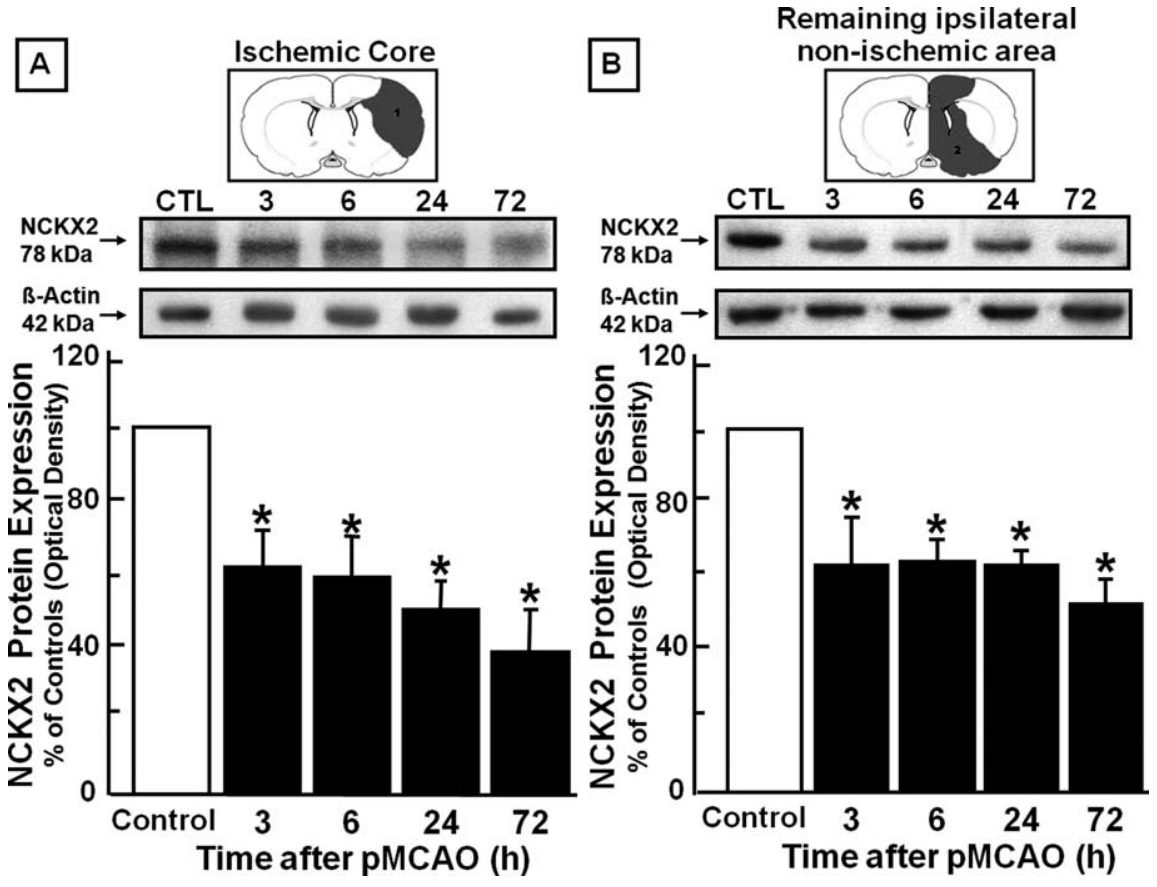

Figure 3. Time course of NCKX2 protein expression after pMCAO in the ischemic core and in the remaining ipsilateral nonischemic area. $\boldsymbol{A}, \boldsymbol{B}$, Western blot and densitometric analysis of NCKX2 protein levels in the ischemic core $(\boldsymbol{A})$ and in the remaining ipsilateral nonischemic area $(\boldsymbol{B})$ are represented. Data were normalized on the basis of $\beta$-actin levels and expressed as a percentage of sham-operated controls. Values represent means $\pm \operatorname{SEM}(n=7) .{ }^{*} p<0.05$ versus control animals.
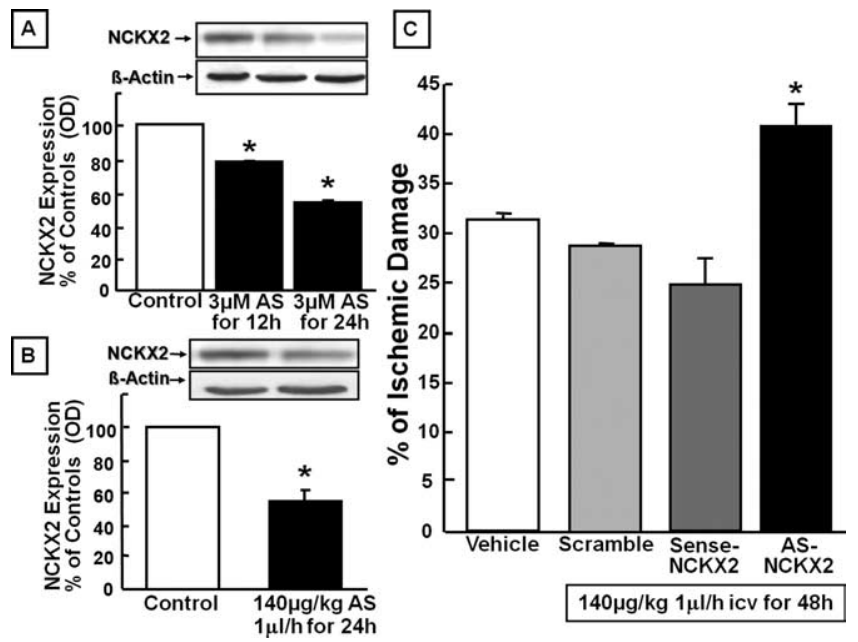

Figure 4. Effect of AS-ODN against NCKX2 on ischemic damage induced in male rats by pMCAO. $A$, Western blot and densitometric analysis of NCKX2 protein in PC12 cells differentiated with NGF and treated with vehicle (control) or $3 \mu \mathrm{M}$ AS-0DN for 12 and $24 \mathrm{~h}$. B, Western blot and densitometric analysis of NCKX2 protein after intracerebroventricular infusion of vehicle (control) or AS-ODN ( $250 \mu \mathrm{m}, 140 \mu \mathrm{g} / \mathrm{kg}, 1 \mu \mathrm{l} / \mathrm{h}$ for $24 \mathrm{~h}$ ) in brain regions of nonischemic rats corresponding to the core and the periinfarct area. Data were normalized on the basis of $\beta$-actin levels and represented as a percentage of NCKX2 expression in control animals. Values represent means $\pm \operatorname{SEM}(n=3) .{ }^{*} p<0.05$ versus NCKX2 levels in controls. $C$, Effect of scrambled, sense, or antisense ODN $(250 \mu \mathrm{m}, 140 \mu \mathrm{g} / \mathrm{kg}, 1 \mu \mathrm{l} / \mathrm{h}$, i.c.v. for $24 \mathrm{~h}$ ) on infarct volume induced by $\mathrm{pMCAO}$. Each column represents the mean \pm SEM of the percentage of the infarct volume compared with the ipsilateral hemisphere. Each ODN was continuously intracerebroventricularly infused by an osmotic minipump ( $1 \mu \mathrm{l} / \mathrm{h})$ for $48 \mathrm{~h}$, starting $24 \mathrm{~h}$ before pMCA0. Control rats received vehicle alone. $n=5-8$ animals in each group. ${ }^{*} p<0.05$ versus vehicle, scrambled, and sense ODN-treated groups.

\section{Results}

Time course of NCKX2 mRNA expression by real-time PCR in the ischemic core and in the area surrounding the ischemic core after $\mathrm{pMCAO}$ in rats

In the ischemic core, NCKX2 mRNA levels displayed a significant decrease $(30 \%) 72 \mathrm{~h}$ after pMCAO, compared with the sham- operated animals (Fig. $1 A$ ). In the ipsilesional area surrounding the ischemic core, a remarkable reduction in NCKX2 (30\%) also occurred starting $9 \mathrm{~h}$ after pMCAO induction (Fig. $1 B$ ), compared with the sham-operated rats. This reduction was still present $72 \mathrm{~h}$ later.

NCKX2 mRNA expression in the prefrontal cortex, cingulate, motor and somatosensory cortices, and caudateputamen of sham-operated and pMCAO-bearing rats evaluated $24 \mathrm{~h}$ after pMCAO

NeuN immunohistochemistry revealed that $24 \mathrm{~h}$ after pMCAO, the ischemic damage encompassed the prefrontal (motor and insular compartments), somatosensory (parietal), and insular cortices, whereas the cingulate and retrosplenial cortices, the caudate-putamen, and the dorsal hippocampus regions were outside the ischemic core and the periinfarct area (Fig. 2C,I). In sham-operated animals, brain distribution of NCKX2 mRNA, obtained by radioactive in situ hybridization (Fig. 2D,J), was largely in agreement with previous studies performed with isoformspecific nonradioactive digoxigeninlabeled antisense riboprobes (Tsoi et al., 1998).

Densitometric measurements of in situ hybridization autoradiographs revealed that in the ipsilesional hemisphere, the PFC1 subregion of the prefrontal cortex (an area belonging to the motor function and located in the ischemic core, $3.2 \mathrm{~mm}$ ahead of the bregma) displayed a remarkable downregulation $(-900 \pm 23$ vs $25 \pm 21)$ in NCKX2 transcripts at $24 \mathrm{~h}$, compared with shamoperated animals (Fig. 2D-F). In the other motor PFC2 subregion, most likely belonging to the periinfarct zone, NCKX2 mRNA decreased significantly $(-198 \pm 46$ vs $32 \pm 42)$ (Fig. $2 D-F)$. No variation in NCKX2 transcripts was detected at $24 \mathrm{~h}$ after pMCAO in the PFC3 subregion, a region outside the core and the periinfarct region and corresponding to the motor and cingulate division of the prefrontal cortices (Fig. 2D-F). Twentyfour hours after pMCAO, NCKX2 transcripts were downregulated $(-858 \pm 35$ versus $-49 \pm 12)$ in the infarct area CTX1, corresponding to the insular and somatosensory cortices and located 0.3 $\mathrm{mm}$ behind the bregma (Fig. $2 J-L$ ). Analogously, in the area most likely corresponding to the periinfarct area, the primary and secondary motor cortices CTX2 displayed a significant decrease $(-268 \pm 50$ vs $-12 \pm 27)$ in NCKX2 transcripts (Fig. $2 J-L)$. In the cingulate cortex, CTX3, an intact region of the ipsilesional hemisphere, NCKX2 transcripts displayed no sig- 
nificant changes (Fig. $2 J-L$ ). Finally, in the caudate-putamen, a subcortical region that was not affected by pMCAO and in which NCKX2 transcripts are largely distributed, this isoform was remarkably reduced $(-177 \pm 79$ vs $12 \pm$ 35) (Fig. 2J-L). No differences in NCKX2 transcript levels were detected in CTX1, CTX2, CTX3, and CPu regions of the hemisphere contralateral to ischemia compared with the corresponding hemisphere of sham-operated rats (see supplemental Fig. 2, available at www.jneurosci.org as supplemental material).

Time course of NCKX2 protein expression evaluated by Western blot in the ischemic core and in the remaining ipsilateral nonischemic area after pMCAO in rats

Analogously to the transcripts levels, in the ischemic core, NCKX2 protein levels were significantly reduced by $50 \%$, compared with control animals, starting $3 \mathrm{~h}$ after pMCAO onset. Interestingly, this reduction was still present $72 \mathrm{~h}$ later (Fig. $3 A$ ). A similar modulation was observed in the ipsilesional area surrounding the ischemic core. Once again, NCKX2 protein levels were reduced by $40 \%$, starting $3 \mathrm{~h}$ after pMCAO, and continued to be low 72 h later, compared with control animals (Fig. 3B). In calpeptin-injected rats, NCKX2 downregulation was prevented both in the ischemic core and in the remaining ipsilateral nonischemic area (see supplemental Fig. 2, available at www.jneurosci.org as supplemental material).

\section{Effect of NCKX2 knock-down by} antisense strategy on the infarct volume induced by $\mathrm{pMCAO}$ in rats

AS-ODN designed against NCKX2 significantly reduced NCKX2 expression in NGF-differentiated PC12 cells. Specifically, the expression was reduced by $20 \%$ and by $45 \%$ at 12 and $24 \mathrm{~h}$, respectively, after cell treatment with AS-ODN (Fig. $4 A)$. A significant reduction (50\%) was also observed in vivo in nonischemic rats in all the brain regions corresponding to the ischemic core and the area surrounding the core $24 \mathrm{~h}$ after AS-ODN infusion (Fig. $4 \mathrm{~B}$ ). When the AS-ODN against NCKX2 was infused intracerebroventricularly by means of an osmotic minipump $24 \mathrm{~h}$ before pMCAO and for an additional $24 \mathrm{~h}$ after the insult, the ischemic volume increased by $32 \%$ (Fig. $4 C$ ). In contrast, when sense and scramble ODNs were administered for the same time period and at the same concentration, they did not affect the infarct volume. Noticeably, AS-ODN was devoid of direct neurotoxic effects, because its intracerebroventricular infusion did not cause any brain damage in normal rats.
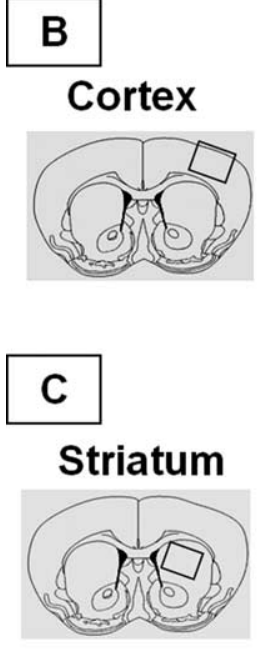
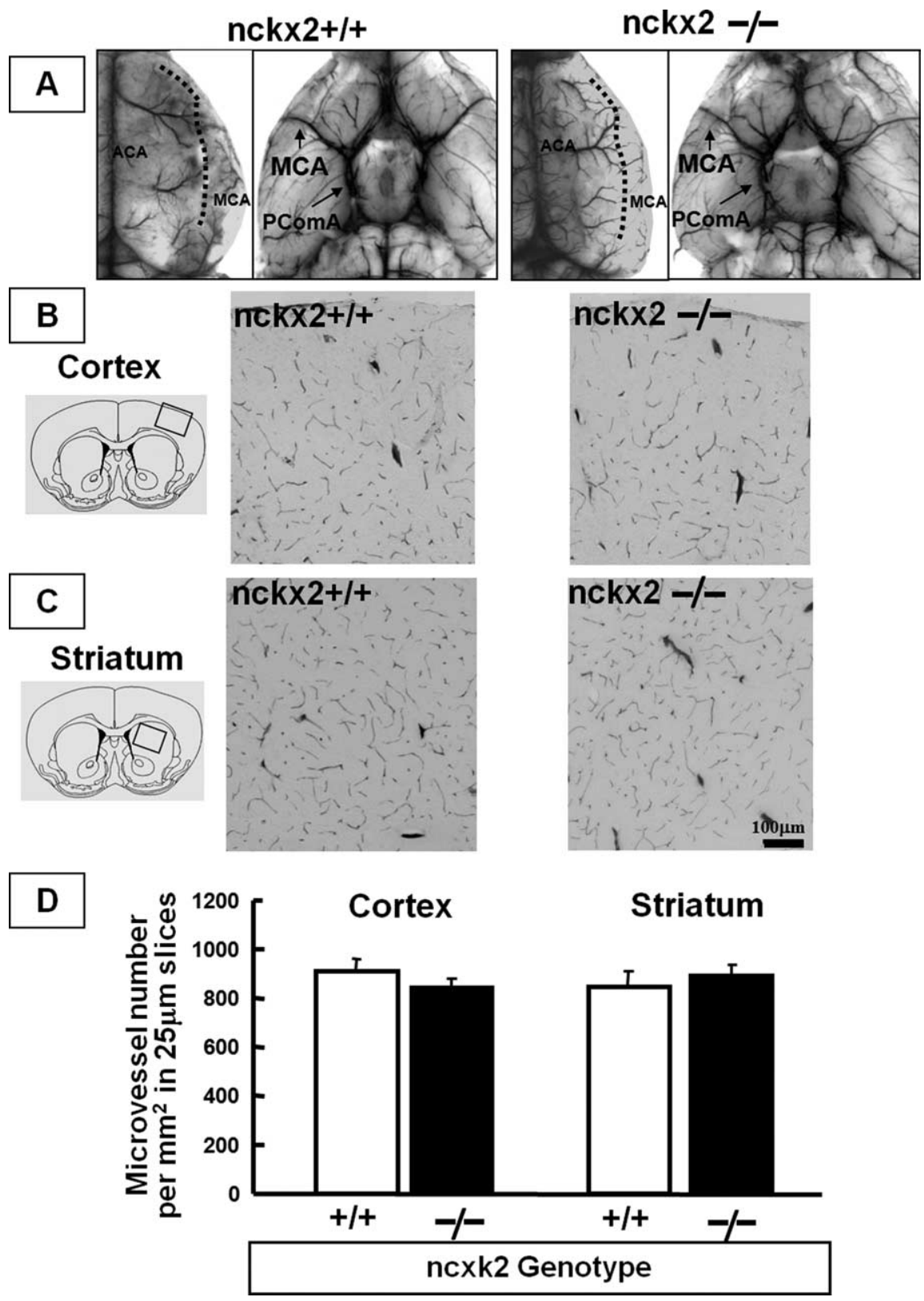

Figure 5. Cerebral vasculature analysis in $n c k \times 2+/+$ and $n c k \times 2-/-$ mice. $\boldsymbol{A}$, Dorsal (left side) and ventral (right side) view of large cerebral blood vessels of $n c k \times 2+/+$ and $n c k \times 2-/-$ mice perfused with Pelikan Ink. The dotted line represents the border between the ACA and MCA territories. $\boldsymbol{B}, \boldsymbol{C}$, Representative microscopic views of microvessel profiles in the cortex $(\boldsymbol{B})$ and striatum $(\boldsymbol{C})$ of $n c k \times 2+/+$ and $n c k \times 2-/-$ mice are shown. $\boldsymbol{D}$, Quantification of microvessel numbers per square millimeter in a $25-\mu \mathrm{m}$-thick slice in the cortex and in the striatum of $n c k \times 2+/+$ and $n c k x 2-/-$ mice. $n=4$ animals for each group. Cortical and striatal capillary densities were expressed as the mean \pm SEM of 15 composite images obtained from each brain.

Effect of $n c k k 2$ knock-out on infarct volume and on neurological scores induced by tMCAO in $n c k \times 2+/+$ and nckx2-/- mice

Examination of large cerebral vessels of the ventral brain side did not show anatomical differences in the circle of Willis between $n c k \times 2+/+$ and $n c k \times 2-/-$ mice. Similarly, cortical and striatal capillary densities did not show significant variations in the two experimental groups (Fig. 5). Quantitative analysis of the size of the PComA revealed no difference in the ratio between $n c k x 2+/+(\mathrm{PComA} / \mathrm{BA}=0.69 \pm 0.16)$ and $n c k x 2-/-$ $(\mathrm{PComA} / \mathrm{BA}=0.75 \pm 0.04)$ mice. Similarly, the boundary between ACA and MCA territory, expressed as the percentage ratio between the area medial to the line of anastomoses and the total 
dorsal area of the hemisphere, was not significantly different between $\mathrm{nckx} 2+/+$ $(\mathrm{ACA} /$ dorsal area $=70.9 \pm 2.5 \% ; n=4)$ and $n c k \times 2-/-($ ACA/dorsal area $=72.4 \pm$ $6.8 ; n=4)$ mice (Fig. 5 ), thus showing that the MCA and ACA territories are not different between $n c k x 2$ wild-type and knockout mice.

Western blot analysis revealed the absence of NCKX2 protein in the brain of $n c k x 2-/-$ mice (Fig. 6A). nckx2 knockout caused a dramatic $130 \%$ increase in the extent of the ischemic lesion in $n c k \times 2-/-$ mice subjected to tMCAO compared with $n c k \times 2+/+$ mice (Fig. 6B). Interestingly, in parallel with the remarkable increase in ischemic volume induced by nckk2 knockout, a statistically significant worsening in both general (Fig. 6D) and focal neurological deficits (Fig. 6E) occurred.

Effect of $n c k k 2$ knock-out on $\left[\mathrm{Ca}^{2+}\right]_{\mathrm{i}}$ in cortical neurons exposed to OGD followed by reoxygenation

To evaluate the functional role of NCKX2 in the regulation of $\mathrm{Ca}^{2+}$ homeostasis during hypoxic conditions, $\left[\mathrm{Ca}^{2+}\right]_{i}$ was detected by means of fura-2 AM in $n c k \times 2+/+$ and $n c k \times 2-/-$ primary cortical neurons exposed to $3 \mathrm{~h}$ of OGD followed by reoxygenation. In normoxic conditions, basal levels of $\left[\mathrm{Ca}^{2+}\right]_{\mathrm{i}}$ were not significantly different between $n c k \times 2+/+$ and $n c k \times 2-/-$ cortical neurons [ $208 \mathrm{nM} \pm 16.0(n=$ $65)$ vs $189 \mathrm{nM} \pm 4.6(n=60)$, respectively]. In $n c k x 2-/-$ primary cortical neurons, 3 h of OGD followed by 4, 6, or 21 h of reoxygenation caused a significantly higher increase in $\left[\mathrm{Ca}^{2+}\right]_{\mathrm{i}}$, at all time intervals, compared with $n c k \times 2+/+$ cortical neurons (Fig. 7A).

Effect of $n c k x 2$ genetic ablation on cell survival in primary cortical neurons exposed to OGD followed by reoxygenation To further confirm that NCKX2 activity contributes to neuronal protection during brain ischemia, we also investigated whether primary cortical neurons from $n c k x 2-/-$ and $n c k x 2+/+$ mice displayed different levels of cell damage when exposed to OGD followed by reoxygenation. In normoxic conditions, cell viability was not different $(\sim 85 \%)$ between $n c k \times 2+/+$ and $n c k \times 2-/-$ primary cortical neurons (Fig. $7 B$ ). When 3 h of OGD were followed by 21 h of reoxygenation, $n c k x 2-/-$ cortical neurons exhibited a greater rate of cell death than that detected in $n c k \times 2+/+$ cortical neurons (Fig. 7B).

Effect of $n c k x 2$ knock-out on $I_{\mathrm{NCKX}}$ in the forward and reverse modes of operation in primary cortical neurons The reversal potential for $I_{\mathrm{NCKX}}$ in wild-type cortical neurons during normoxic conditions was estimated to be $-10 \mathrm{mV}$. This value was much greater than the reversal potential reported for $I_{\mathrm{NCX}}(-40 \mathrm{mV})$ (Hilgemann et al., 1991). This large difference between the reversal potential of $I_{\mathrm{NCKX}}$ estimated in the present study and that reported for $I_{\mathrm{NCX}}$, together with the inhibitory effect on NCX currents (Zhang and Hancox, 2003) exerted by the high external $\mathrm{K}^{+}$concentrations $(50 \mathrm{~mm})$ used in the present

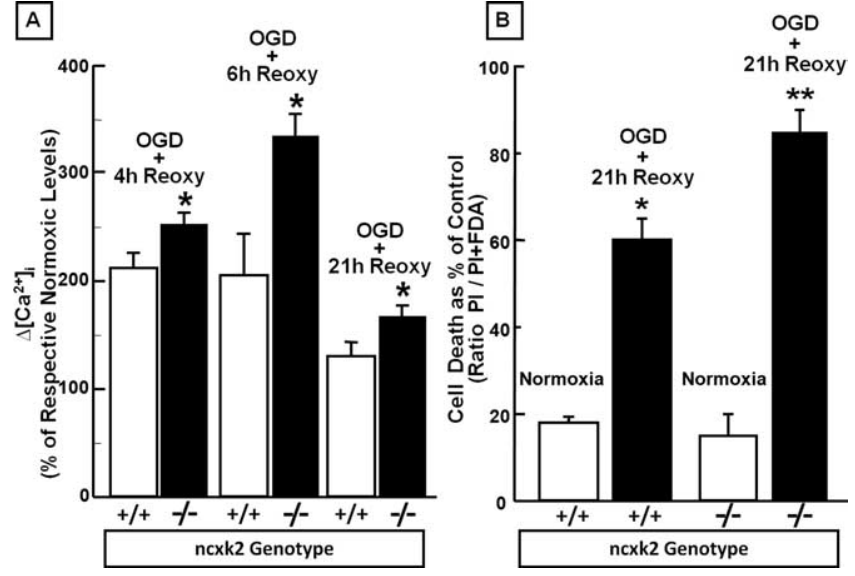

Figure 7. Effect of $n c k k 2$ genetic ablation on $\left[\mathrm{Ca}^{2+}\right]_{\mathrm{i}}$ in cortical neurons exposed to OGD followed by reoxygenation and on cell survival in cortical neurons exposed to OGD plus reoxygenation. $\boldsymbol{A}$, The bar graph depicts the quantification of $\left[\mathrm{Ca}^{2+}\right]_{i}$ detected with fura-2 AM in 7-10 DIV cortical neurons from $n c k \times 2+/+$ and $n c k \times 2-/-$ mice exposed to $3 \mathrm{~h}$ of $0 \mathrm{GD}$ followed by 4,6 , and $21 \mathrm{~h}$ of reoxygenation and expressed as $\Delta \%\left[\mathrm{Ca}^{2+}\right]_{i}$ of the respective normoxic $\left[\mathrm{Ca}^{2+}\right]_{i}$ levels. ${ }^{*} p<0.05$ versus respective normoxic basal level and versus $n c k \times 2+/+$. Each bar represents the mean \pm SEM of the at least 70 experimental values studied in three independent experimental sessions. $\boldsymbol{B}$, The quantification of cell death occurring in 7-10 DIV cortical neurons from $n c k \times 2+/+$ and $n c k \times 2-/-$ mice exposed to $3 \mathrm{~h}$ of $0 \mathrm{GD}$ followed by $21 \mathrm{~h}$ of reoxygenation is shown. Sister cultures were incubated for $24 \mathrm{~h}$ in normoxic buffers and constituted the internal controls. At the end of the experiments, cells were stained with PI and fluorescein, and images were acquired as reported in Material and Methods. The data are reported as the percentage of cell death occurring in each group compared with its respective normoxic cells. ${ }^{*} p<0.05$ versus respective normoxic neurons; ${ }^{* *} p<0.05$ versus its normoxic neurons and $n c k \times 2+/+$ neurons exposed to $3 \mathrm{~h}$ of $0 \mathrm{GD}$ followed by $21 \mathrm{~h}$ of reoxygenation. Each bar represents the mean \pm SEM of three different experimental values. 


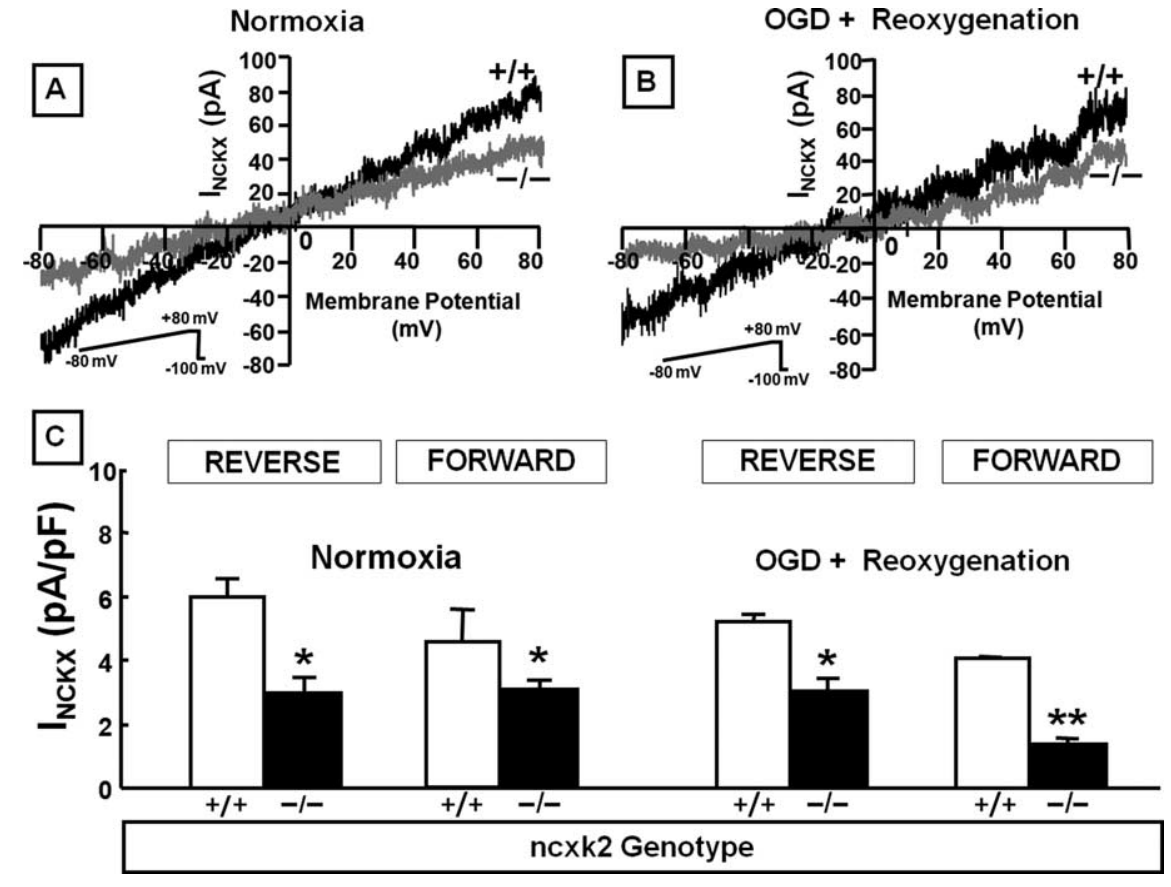

Figure 8. Effect of $n c k x 2$ knock-out on $I_{\mathrm{NCKX}}$ recorded in 7-10 DIV embryonic cortical neurons. $\boldsymbol{A}, \boldsymbol{B}, I_{\mathrm{NCKX}}$ superimposed traces recorded from $n c k \times 2+/+$ (black traces) and $n c k \times 2-/-$ (gray traces) cortical neurons under normoxic conditions (left) and after $3 \mathrm{~h}$ of $0 G \mathrm{G}$ followed by $4 \mathrm{~h}$ of reoxygenation (right). $C, I_{\mathrm{NCKX}}$ quantification expressed as pA/pF in $n c k x 2+/+$ and $n c k x 2-/-$ cortical neurons in normoxia and after $3 \mathrm{~h}$ of $0 \mathrm{GD}$ followed by $4 \mathrm{~h}$ of reoxygenation. The values are expressed as mean \pm SEM of current densities recorded from 15 cells in each experimental group obtained from three independent experimental sessions. ${ }^{*} p<0.05$ versus $n c k x 2+/+$ neurons; ${ }^{* *} p<0.05$ versus $n c k x 2-/-$ normoxic neurons.

study, allows us to exclude a relevant $I_{\mathrm{NCX}}$ contamination of the recorded $I_{\mathrm{NCKX}}$.

In normoxic conditions, isolated $I_{\mathrm{NCKX}}$, recorded in both the forward and reverse modes of operation in $n c k \times 2-/-$ primary cortical neurons, was significantly lower than that detected in $n c k x 2+/+$ (Fig. $8 A, C)$. It is clear that the current magnitude decreases in the knock-out, so it seems likely that NCKX2 current is part of the current measured. More relevantly, also during anoxic conditions, the currents carried by NCKX in the forward and reverse modes of operation were significantly reduced in primary cortical neurons obtained from $n c k \times 2-/-$ mice compared with wild-type mice (Fig. $8 B, C$ ). Intriguingly, $I_{\mathrm{NCKX}}$ recorded in the forward mode of operation after anoxia followed by reoxygenation was significantly lower in $n c k x 2-/-$ cortical neurons than in normoxic $n c k x 2-/-$ neurons (Fig. $8 C$ ).

\section{Discussion}

The results of the present study clearly demonstrated for the first time that both knocking down and knocking out NCKX2 expression dramatically increased the extent of the ischemic lesion in rats and mice subjected to pMCAO and tMCAO, respectively. Interestingly, the enlargement of the infarct observed in $n c k x 2$ knock-out mice was associated with a worsening of focal and general neurological deficits. Moreover, focal cerebral ischemia caused relevant changes in the pattern of both NCKX2 mRNA and protein expression in the ischemic core and in the remaining ipsilateral nonischemic area. In accordance with the in vivo data, we found that $n c k \times 2-/-$ primary cortical neurons displayed a higher vulnerability to hypoxic conditions compared with $n c k x 2+/+$ cells. In particular, $\left[\mathrm{Ca}^{2+}\right]_{\mathrm{i}}$ significantly increased in $n c k x 2-1-$ neurons compared with that detected in $n c k \times 2+/+$ cortical neurons exposed to OGD followed by reoxygenation. In addition, under hypoxic conditions, $I_{\mathrm{NCKX}}$ recorded in the forward and reverse modes of operation in $n c k \times 2-/-$ neurons was significantly lower than that recorded in $n c k \times 2+/+$ cortical neurons.

All these findings indicate that the disruption of $n c k x 2$ gene by genetic manipulation renders neurons more susceptible to the ischemic insult and that NCKX2 activity attenuates the development of brain injury elicited by ischemia in those cerebral territories supplied by MCA. Furthermore, the critical role of NCKX2 during ischemia was highlighted by the increase in the infarct volume obtained in two different rodent models of pMCAO and tMCAO. Interestingly, enlargement of the ischemic lesion was also observed when NCKX2 expression was only partially reduced following AS-ODN treatment.

The dramatic consequences in the development of ischemic damage and in the death of cortical neurons after $n c k x 2$ ablation might be attributed to the relevant role that NCKX2 can play compared with the other members of the NCX superfamily in extruding calcium ions when it operates in the forward mode. In fact, this $\mathrm{K}^{+}$dependent exchanger isoform, unlike NCKX3 and NCKX4, may be only activated when extracellular $\mathrm{K}^{+}$concentrations overcome the physiological levels, being provided with a $K_{\mathrm{d}}$ of $\sim 40 \mathrm{~mm}$ (Lee et al., 2002; Visser et al., 2007). Interestingly, during the early phases of brain ischemia, extracellular $\mathrm{K}^{+}$concentrations reach, in the ischemic core, levels higher than those corresponding to the $K_{\mathrm{d}}$ of external $\mathrm{K}^{+}$binding sites for NCKX2 (Gido et al., 1997; Visser et al., 2007). That NCKX2 might work in the forward mode during hypoxia is supported by the electrophysiological results obtained in the present study and showing that $I_{\mathrm{NCKX}}$, recorded in the forward mode of operation, was significantly reduced in anoxic $n c k \times 2-/-$ cortical neurons, compared with $n c k x 2+/+$. This suggests that during hypoxia, the currents carried by NCKX2 operating in the forward mode play a relevant role in the pathogenesis of the ischemic damage. Accordingly, we found that a remarkable elevation of $\left[\mathrm{Ca}^{2+}\right]_{i}$ and a consequent neuronal death occurred in cortical $n c k x 2-/-$ neurons. However, we cannot exclude that, in some brain regions closer to the territory supplied by MCA, and in some stages of the ischemic process, the transmembrane ionic gradients of $\mathrm{Na}^{+}, \mathrm{K}^{+}$, and $\mathrm{Ca}^{2+}$ might favor NCKX2 to operate in the reverse mode, thus causing the extrusion of $\mathrm{Na}^{+}$ions and the influx of $\mathrm{K}^{+}$and $\mathrm{Ca}^{2+}$ ions. Indeed, the electrophysiological experiments of the present study demonstrated that, also in the reverse mode of operation, $I_{\mathrm{NCKX}}$ was lower in $n c k \times 2-/-$ than in $n c k \times 2+/+$ cortical neurons exposed to hypoxia. However, it should be underlined that the increase in extracellular $\mathrm{K}^{+}$that is associated with spreading depression, a phenomenon occurring during the ischemic process, may activate this potassium-dependent exchanger, which, in turn, might contribute to attenuate subsequent waves of depolarization. In this way, knocking down and knocking out of NCKX2 might enhance the phenomenon of spreading depression and could account for the increase in infarct volume. 
As far as the mechanisms responsible for the NCKX2 protein downregulation after brain ischemia are concerned, NCKX2 reduction in the ischemic core and in the remaining ipsilateral nonischemic area could be ascribed to its cleavage by proteolytic enzymes, which are activated during anoxia, as it has been demonstrated for another member of the NCX superfamily, NCX3 (Bano et al., 2005). This hypothesis is supported by our findings showing that NCKX2 downregulation was prevented by the treatment with the calpain inhibitor calpeptin $3 \mathrm{~h}$ after pMCAO.

Finally, it should be also underlined that we have previously demonstrated that the selective knock-down of the two $\mathrm{K}^{+}$independent members of the cation/ $\mathrm{Ca}^{2+}$ exchanger superfamily, NCX1 and NCX3, exacerbates the ischemic damage (Pignataro et al., 2004b, Secondo et al., 2007).

Overall, our results indicate that NCKX2 has a nonredundant role in the maintenance of $\mathrm{Ca}^{2+}$ homeostasis during conditions of high extracellular $\mathrm{K}^{+}$concentration, because it occurs in neurons during cerebral ischemia. Therefore, NCKX2 emerges as a new potential target to be investigated in the study of the molecular mechanisms involved in cerebral ischemia.

\section{References}

Annunziato L, Pignataro G, Di Renzo GF (2004) Pharmacology of brain $\mathrm{Na}+/ \mathrm{Ca} 2+$ exchanger: from molecular biology to therapeutic perspectives. Pharmacol Rev 56:633-654.

Bano D, Young KW, Guerin CJ, Lefeuvre R, Rothwell NJ, Naldini L, Rizzuto R, Carafoli E, Nicotera P (2005) Cleavage of the plasma membrane $\mathrm{Na}+/ \mathrm{Ca} 2+$ exchanger in excitotoxicity. Cell 120:275-285.

Blaustein MP, Lederer WJ (1999) Sodium/calcium exchange: its physiological implications. Physiol Rev 79:763-854.

Boscia F, Gala R, Pignataro G, de Bartolomeis A, Cicale M, AmbesiImpiombato A, Di Renzo G, Annunziato L (2006) Permanent focal brain ischemia induces isoform-dependent changes in the pattern of $\mathrm{Na}+/ \mathrm{Ca} 2+$ exchanger gene expression in the ischemic core, periinfarct area, and intact brain regions. J Cereb Blood Flow Metab 26:502-517.

Cai X, Lytton J (2004) The cation/Ca(2+) exchanger superfamily: phylogenetic analysis and structural implications. Mol Biol Evol 21:1692-1703.

Clark WM, Lessov NS, Dixon MP, Eckenstein F (1997) Monofilament intraluminal middle cerebral artery occlusion in the mouse. Neurol Res 19:641-648.

Dong H, Light PE, French RJ, Lytton J (2001) Electrophysiological characterization and ionic stoichiometry of the rat brain $\mathrm{K}^{+}$-dependent $\mathrm{Na}^{+} /$ $\mathrm{Ca}^{2+}$ exchanger, NCKX2. J Biol Chem 276:25919-25928.

Gido G, Kristian T, Siesjo BK (1997) Extracellular potassium in a neocortical core area after transient focal ischemia. Stroke 28:206-210.

Grynkiewicz G, Poenie M, Tsien RY (1985) A new generation of Ca2 + indicators with greatly improved fluorescence properties. J Biol Chem 260:3440-3450.

Kim MH, Lee SH, Park KH, Ho WK (2003) Distribution of $\mathrm{K}^{+}$-dependent $\mathrm{Na}^{+} / \mathrm{Ca}^{2+}$ exchangers in the rat supraoptic magnocellular neuron is polarized to axon terminals. J Neurosci 23:11673-11680.

Kim MH, Korogod N, Schneggenburger R, Ho WK, Lee SH (2005) Interplay between $\mathrm{Na}^{+} / \mathrm{Ca}^{2+}$ exchangers and mitochondria in $\mathrm{Ca}^{2+}$ clearance at the calyx of Held. J Neurosci 25:6057-6065.

Kitagawa K, Matsumoto M, Yang G, Mabuchi T, Yagita Y, Hori M, Yanagihara T (1998) Cerebral ischemia after bilateral carotid artery occlusion and intraluminal suture occlusion in mice: evaluation of the patency of the posterior communicating artery. J Cereb Blood Flow Metab 18:570-579.

Kraev A, Quednau BD, Leach S, Li XF, Dong H, Winkfein R, Perizzolo M, Cai X, Yang R, Philipson KD, Lytton J (2001) Molecular cloning of a third member of the potassium-dependent sodium-calcium exchanger gene family, NCKX3. J Biol Chem 276:23161-23172.

Hilgemann DW, Nicoll DA, Philipson KD (1991) Charge movement during $\mathrm{Na}+$ translocation by native and cloned cardiac $\mathrm{Na}+/ \mathrm{Ca} 2+$ exchanger. Nature 352:715-718.

Huang Z, Huang PL, Panahian N, Dalkara T, Fishman MC, Moskowitz MA (1994) Effects of cerebral ischemia in mice deficient in neuronal nitric oxide synthase. Science 265:1883-1885.
Lamason RL, Mohideen MA, Mest JR, Wong AC, Norton HL, Aros MC, Jurynec MJ, Mao X, Humphreville VR, Humbert JE, Sinha S, Moore JL, Jagadeeswaran P, Zhao W, Ning G, Makalowska I, McKeigue PM, O’Donnell D, Kittles R, Parra EJ, et al. (2005) SLC24A5, a putative cation exchanger, affects pigmentation in zebrafish and humans. Science 310:1782-1786.

Lee SH, Kim MH, Park KH, Earm YE, Ho WK (2002) $\mathrm{K}^{+}$-dependent $\mathrm{Na}^{+} /$ $\mathrm{Ca}^{2+}$ exchange is a major $\mathrm{Ca}^{2+}$ clearance mechanism in axon terminals of rat neurohypophysis. J Neurosci 22:6891-6899.

Li XF, Kraev AS, Lytton J (2002) Molecular cloning of a fourth member of the potassium-dependent sodium-calcium exchanger gene family, NCKX4. J Biol Chem 50:48410-48417.

Li XF, Kiedrowski L, Tremblay F, Fernandez FR, Perizzolo M, Winkfein RJ, Turner RW, Bains JS, Rancourt DE, Lytton J (2006) Importance of K+dependent $\mathrm{Na}+/ \mathrm{Ca} 2+$-exchanger 2, NCKX2, in motor learning and memory. J Biol Chem 281:6273-6282.

Li Z, Matsuoka S, Hryshko LV, Nicoll DA, Bersohn MM, Burke EP, Lifton RP, Philipson KD (1994) Cloning of the NCX2 isoform of the plasma membrane $\mathrm{Na}+-\mathrm{Ca} 2+$ exchanger. J Biol Chem 269:17434-17439.

Lipton P (1999) Ischemic cell death in brain neurons. Physiol Rev 79:1431-1568.

Lo AC, Cheung AK, Hung VK, Yeung CM, He QY, Chiu JF, Chung SS, Chung SK (2007) Deletion of aldose reductase leads to protection against cerebral ischemic injury. J Cereb Blood Flow Metab 27:1496-1509.

Longa EZ, Weinstein PR, Carlson S, Cummins R (1989) Reversible middle cerebral artery occlusion without craniectomy in rats. Stroke 20:84-91.

Lytton J, Li XF, Dong H, Kraev A (2002) K+-dependent Na+/Ca2 + exchangers in the brain. Ann NY Acad Sci 976:382-393.

Maeda K, Hata R, Hossmann KA (1998) Differences in the cerebrovascular anatomy of C57black/6 and SV129 mice. NeuroReport 9:1261-1265.

Matrone C, Pignataro G, Molinaro P, Irace C, Scorziello A, Di Renzo GF, Annunziato L (2004) HIF-1 $\alpha$ reveals a binding activity to the promoter of iNOS gene after permanent middle cerebral artery occlusion. J Neurochem 90:368-378.

Nicoll DA, Longoni S, Philipson KD (1990) Molecular cloning and functional expression of the cardiac sarcolemmal Na+-Ca2 + exchanger. Science 250:562-565.

Nicoll DA, Hryshko LV, Matsuoka S Frank JS, Philipson KD (1996) Mutation of amino acid residues in the putative transmembrane segments of the cardiac sarcolemmal $\mathrm{Na}+-\mathrm{Ca} 2+$ exchanger. J Biol Chem 271:13385-13391.

Pannaccione A, Secondo A, Scorziello A, Cali G, Taglialatela M, Annunziato L (2005) Nuclear factor-kappaB activation by reactive oxygen species mediates voltage-gated $\mathrm{K}+$ current enhancement by neurotoxic betaamyloid peptides in nerve growth factor-differentiated PC-12 cells and hippocampal neurones. J Neurochem 94:572-586.

Paxinos G, Franklin KBJ (2000) The mouse brain stereotaxic coordinates. New York: Academic.

Paxinos G, Watson C (1998) The rat brain in stereotaxic coordinates. New York: Academic.

Pignataro G, Gala R, Cuomo O, Tortiglione A, Giaccio L, Castaldo P, Sirabella R, Matrone C, Canitano A, Amoroso S, Di Renzo G, Annunziato L (2004a) Two sodium/calcium exchanger gene products, NCX1 and NCX3, play a major role in the development of permanent focal cerebral ischemia. Stroke 35:2566-2570.

Pignataro G, Tortiglione A, Scorziello A, Giaccio L, Secondo A, Severino B, Santagada V, Caliendo G, Amoroso S, Di Renzo G, Annunziato L (2004b) Evidence for a protective role played by the $\mathrm{Na}+/ \mathrm{Ca} 2+$ exchanger in cerebral ischemia induced by middle cerebral artery occlusion in male rats. Neuropharmacology 46:439-448.

Pignataro G, Simon RP, Xiong ZG (2007) Prolonged activation of ASIC1a and the time window for neuroprotection in cerebral ischaemia. Brain 130:151-158.

Prinsen CFM, Szerencsei RT, Schnetkamp PPM (2000) Molecular cloning and functional expression of the potassium-dependent sodium-calcium exchanger from human and chicken retinal cone photoreceptors. J Neurosci 20:1424-1434.

Reilander H, Achilles A, Friedel U, Maul G, Lottspeich F, Cook NJ (1992) Primary structure and functional expression of the $\mathrm{Na} / \mathrm{Ca}, \mathrm{K}$-exchanger from bovine rod photoreceptors. EMBO J 11:1689-1695.

Schwarz EM, Benzer S (1997) Calx, a Na-Ca exchanger gene of Drosophila melanogaster. Proc Natl Acad Sci USA 94:10249-10254. 
Scorziello A, Santillo M, Adornetto A, Dell'aversano C, Sirabella R, Damiano S, Canzoniero LM, Renzo GF, Annunziato L (2007) NO-induced neuroprotection in ischemic preconditioning stimulates mitochondrial MnSOD activity and expression via RAS/ERK1/2 pathway. J Neurochem 103:1472-1480

Scremin OU (1995) Cerebral vascular system. In: The rat nervous system (Paxinos G, ed), pp 3-35. New York: Academic.

Secondo A, Staiano RI, Scorziello A, Sirabella R, Boscia F, Adornetto A, Valsecchi V, Molinaro P, Canzoniero LM, Di Renzo G, Annunziato L (2007) BHK cells transfected with NCX3 are more resistant to hypoxia followed by reoxygenation than those transfected with NCX1 and NCX2: possible relationship with mitochondrial membrane potential. Cell Calcium 42:521-535.

Tamura A, Graham DI, McCulloch J, Teasdale GM (1981) Focal cerebral ischemia in the rat: I. Description of technique and early neuropathological consequences following middle cerebral artery occlusion. J Cereb Blood Flow Metab 1:53-60.

Tortiglione A, Minale M, Pignataro G, Secondo A, Scorziello A, Di Renzo GF,
Amoroso S, Caliendo G, Santagada V, Annunziato L (2002) The 2-oxopyrrolidinacetamide piracetam reduces infarct brain volume induced by permanent middle cerebral artery occlusion in male rats. Neuropharmacology 43:427-433.

Tsoi M, Rhee KH, Bungard D, Li XF, Lee SL, Auer RN, Lytton J (1998) Molecular cloning of a novel potassium-dependent sodium-calcium exchanger from rat brain. J Biol Chem 273:4155-4162.

Visser F, Valsecchi V, Annunziato L, Lytton J (2007) Exchangers NCKX2, NCKX3, and NCKX4: identification of Thr-551 as a key residue in defining the apparent $\mathrm{K}^{+}$affinity of NCKX2. J Biol Chem 282:4453-4462.

Yaida Y, Nowak TS (1995) Distribution of phosphodiester and phosphorothioate oligodeoxynucleotides in rat brain after intraventricular and intra-hippocampal administration determined by in situ hybridization. Regul Pept 59:193-199.

Zhang YH, Hancox JC (2003) Evidence for a modulatory effect of external potassium ions on ionic current mediated by the cardiac $\mathrm{Na}+-\mathrm{Ca} 2+$ exchanger. Cell Calcium 33:49-58. 